Journal of Zhejiang University-SCIENCE A (Applied Physics \& Engineering)

ISSN 1673-565X (Print); ISSN 1862-1775 (Online)

www.zju.edu.cn/jzus; www.springerlink.com

E-mail: jzus@zju.edu.cn

\title{
A nonlinear cumulative evolution model for corrosion fatigue damage
}

\author{
Zhong-ying $\mathrm{HAN}^{1}$, Xiao-guang $\mathrm{HUANG}^{\dagger 2}$, Yu-guang $\mathrm{CAO}^{2}$, Jin-quan $\mathrm{XU}^{3}$ \\ $\left({ }^{1}\right.$ College of Petroleum Engineering, China University of Petroleum, Qingdao 266580, China) \\ $\left({ }^{2}\right.$ College of Pipeline and Civil Engineering, China University of Petroleum, Qingdao 266580, China) \\ $\left({ }^{3}\right.$ School of Naval Architecture, Ocean and Civil Engineering, Shanghai Jiao Tong University, Shanghai 200240, China) \\ †E-mail: huangupc@126.com; huangxg@upc.edu.cn \\ Received Oct. 29, 2013; Revision accepted Feb. 17, 2014; Crosschecked May 21, 2014
}

\begin{abstract}
A nonlinear cumulative evolution model for corrosion fatigue damage was proposed. Corrosion fatigue damage was considered as a nonlinear cumulative result of stress corrosion damage and fatigue damage. The influences of stress corrosion damage and fatigue damage on corrosion fatigue damage and damage evolution life were studied from a phenomenological point of view. The relevant damage parameters were determined by the experimental results of the LY12CZ aluminum alloy, and the corrosion fatigue life evaluation model based on damage evolution law was established. The corrosion fatigue life predicted by evaluation model agrees well with the experimental result. The damage evolution model in this study can provide a new method for theoretical research and life prediction of corrosion fatigue.
\end{abstract}

Key words: Corrosion fatigue, Stress corrosion, Nonlinear accumulation, Damage evolution doi: 10.1631 /jzus.A1300362

Document code: A

CLC number: TG174

\section{Introduction}

Corrosion fatigue is recognized as one of the significant degradation mechanisms that affect the reliability and durability of metal components and structures (Tang and Li, 2007; Bhuiyan et al., 2008; Ishihara et al., 2008; Zhao et al., 2012; Huang and Xu, 2013; Misak et al., 2013). Corrosion fatigue phenomenon is very common in marine and aerospace engineering, but there are many other issues which still do not have good solutions to this problem. With the flourish of damage mechanics (Lemaitre, 1985; Lemaitre and Chaboche, 1990; Fatemi and Vangt, 1998; Jain and Ghosh, 2008; Besson, 2010;

\footnotetext{
${ }^{\ddagger}$ Corresponding author

* Project supported by the National Natural Science Foundation of China (No. 11242004), the Fundamental Research Funds for the Central Universities (No. 13CX02091A), and the Focus Technology Development Plan of the Qingdao Economic and Technological Development Zone (No. 2013-1-53), China

(C) Zhejiang University and Springer-Verlag Berlin Heidelberg 2014
}

Ohata et al., 2010), some researchers tried to study corrosion fatigue behavior of metals from the perspective of damage evolution, and proposed some corrosion fatigue damage evaluation methods (Kotsikos et al., 1999; Kermanidis et al., 2005).

Corrosion fatigue damage is the property degradation process of materials caused by the constant initiation, propagation and merger of internal defects, under the interaction of cyclic loads and a corrosive environment, which can obviously accelerate the corrosion fatigue damage evolution, which is caused by the coupling effect of stress corrosion damage and fatigue damage. In general, the evolution of fatigue damage is cycle-dependent, while the accumulation of stress corrosion damage is time-dependent, so the meso-mechanism of this coupling is very complex. To simplify the characterization of corrosion fatigue damage, a nonlinear cumulative model of corrosion fatigue damage is proposed in this paper. Based on Miner's linear cumulative damage theory, the corrosion fatigue damage is dealt as the nonlinear 
accumulation of stress corrosion damage controlled by the average stress and fatigue damage controlled by the stress amplitude. The corrosion fatigue experiments of the LY12CZ aluminum alloy are designed to determine the relative damage parameters and establish the corrosion fatigue damage evolution law. Such an approach is practical and useful for the simulation of the entire corrosion fatigue damage process and the remaining life assessment in aging aircraft and ocean structures.

\section{Theoretical model}

\subsection{Stress corrosion damage}

The researches related to stress corrosion damage at present mainly adopt the continuum damage mechanics methods. These methods do not consider the variation of the internal microstructure of the material, but instead construct the damage constitutive equations and evolution equation by introducing the damage variables in different forms from a macro perspective to achieve the harmony of theoretical predictions and experimental results.

Generally, stress corrosion damage and its evolution are controlled by the mechanical properties of material and external factors such as static load, temperature, and corrosive environments. Therefore, the stress corrosion damage variable $D_{\mathrm{c}}$ is expressed as the formula of effective stress $\sigma$, stress corrosion threshold stress $\sigma_{\text {th }}$, time $t$, temperature $T$, and the $\mathrm{pH}$ value of solution, i.e.,

$$
D_{\mathrm{c}}=F_{\mathrm{c}}\left(\sigma, \sigma_{\mathrm{th}}, t, T, \mathrm{pH}, \cdots\right)
$$

where the effective stress is shown as $\sigma=P / A, P$ is the load, and $A$ is the effective bearing area.

In a specific experimental environment, the variation of temperature and $\mathrm{pH}$ value can be ignored, so the stress corrosion damage law is simplified as

$$
\frac{\mathrm{d} D_{\mathrm{c}}}{\mathrm{d} t}=f_{\mathrm{c}}\left(\sigma, \sigma_{\mathrm{th}}, D_{\mathrm{c}}\right)
$$

where $f_{\mathrm{c}}()$ is the derivative of $F_{\mathrm{c}}()$ with time.

When the effective stress of the specimen is less than threshold stress, tensile stress corrosion damage does not happen. Therefore, the stress corrosion damage evolution model can be simplified as (Chaboche, 1988a; 1988b; Wu et al., 2004; Alamilla et al., 2009; Raykar et al., 2011)

$$
\frac{\mathrm{d} D_{\mathrm{c}}}{\mathrm{d} t}=\left\{\begin{array}{l}
\kappa \frac{\left(\sigma-\sigma_{\mathrm{th}}\right)^{p}}{\left(1-D_{\mathrm{c}}\right)^{q}}, \sigma>\sigma_{\mathrm{th}}, \\
0, \sigma \leq \sigma_{\mathrm{th}},
\end{array}\right.
$$

where $\kappa, p$, and $q$ are material constants related to environment.

\subsection{Corrosion fatigue damage model}

In the conventional damage theory, time is always used as the reference variable for damage evolution. However, for fatigue caused by cyclic loading, the damage accumulates with load cycles, so the form of the fatigue damage evolution equation is often written as

$$
\frac{\mathrm{d} D_{\mathrm{f}}}{\mathrm{d} N}=F_{\mathrm{f}}\left(\sigma_{\max }, \sigma_{0}, D_{\mathrm{f}}, T, \cdots\right)
$$

where $D_{\mathrm{f}}$ is the fatigue damage variable, $N$ is the load cycle, $\sigma_{\max }$ is the maximum stress, and $\sigma_{0}$ is the average stress.

If only the influence of cyclic stress amplitude $\sigma_{\mathrm{a}}$ is considered in the above fatigue damage model, fatigue damage per cycle can be simplified as (Chaboche, 1981; Fatemi and Vangt, 1998; Zhang et al., 2011)

$$
\frac{\mathrm{d} D_{\mathrm{f}}}{\mathrm{d} N}=(1-D)^{-\mu}\left(\frac{\sigma_{\mathrm{a}}}{M\left(\sigma_{0}\right)}\right)^{B},
$$

where $D$ is the corrosion fatigue damage variable, $\mu$ and $B$ are experimental constants, and $M\left(\sigma_{0}\right)$ is a material parameter relative to average stress.

The corrosion fatigue damage is caused by the interactions of corrosive environment and cyclic loading, but it is essentially different from stress corrosion damage and fatigue damage. In this study, the idea is proposed that stress corrosion damage and fatigue damage occur during the corrosion fatigue process and mutually reinforce the damage evolution. 
Consequently, corrosion fatigue damage is dealt with as the accumulation of stress corrosion damage and fatigue damage.

If the stress corrosion damage and fatigue damage accumulate linearly, the corrosion fatigue damage increment can be written as

$$
\mathrm{d} D=f_{\mathrm{c}} \mathrm{d} t+F_{\mathrm{f}} \mathrm{d} N .
$$

The linear damage accumulation model is simple, but its prediction is too inaccurate to be adopted. In contrast, the nonlinear cumulative damage evolution law is more acceptable for most materials, namely,

$$
\mathrm{d} D=(1-D)^{-\omega} f_{\mathrm{c}} \mathrm{d} t+F_{\mathrm{f}} \mathrm{d} N
$$

where $\omega$ is the non-negative damage cumulative exponent.

Combined with the nonlinear accumulation method, the corrosion fatigue damage evolution law can be rewritten as

$$
\frac{\mathrm{d} D}{\mathrm{~d} N}=\kappa f\left(\sigma-\sigma_{\mathrm{th}}\right)^{p}(1-D)^{-\psi}+(1-D)^{-\mu}\left(\frac{\sigma_{\mathrm{a}}}{M\left(\sigma_{0}\right)}\right)^{B},
$$

where $f$ is the cyclic load frequency, and $\psi=q+\omega$.

Introducing $N_{\mathrm{f}}$ to characterize the load cycles of fatigue failure and modifying the stress corrosion failure life in the form of a cycle number, denoted as $N_{\mathrm{c}}$, according to the respective damage evolution law, we have

$$
\begin{aligned}
& N_{\mathrm{f}}=\frac{1}{(\mu+1)}\left(\frac{\sigma_{\mathrm{a}}}{M\left(\sigma_{0}\right)}\right)^{-B}, \\
& N_{\mathrm{c}}=\frac{1}{\kappa f(1+\psi)\left(\sigma-\sigma_{\mathrm{th}}\right)^{p}} .
\end{aligned}
$$

Substituting Eqs. (9) and (10) into Eq. (8), the corrosion fatigue damage evolution law equation is rewritten as

$$
\frac{\mathrm{d} D}{\mathrm{~d} N}=\frac{(1-D)^{-\psi}}{(1+\psi) N_{\mathrm{c}}}+\frac{(1-D)^{-\mu}}{(1+\mu) N_{\mathrm{f}}}
$$

Integrating Eq. (11), the corrosion fatigue life based on the damage evolution law is obtained as

$$
\frac{N}{N_{\mathrm{c}}}=\int_{0}^{1}\left(\frac{(1-D)^{-\psi}}{(1+\psi)}+\frac{N_{\mathrm{c}}(1-D)^{-\mu}}{N_{\mathrm{f}}(1+\mu)}\right)^{-1} \mathrm{~d} D .
$$

\section{Experiments on damage parameters determination}

\subsection{Materials and specimens}

To determine the damage parameters of the above corrosion fatigue damage evolution model, experiments for corrosion fatigue and stress corrosion are designed. The sample material is the $\mathrm{LY} 12 \mathrm{CZ}$

\begin{tabular}{|c|c|c|c|}
\hline $\begin{array}{l}\text { Young's } \\
\text { Modulus, } \\
E(\mathrm{GPa})\end{array}$ & $\begin{array}{l}\text { Yield limit, } \\
\sigma_{0.2}(\mathrm{MPa})\end{array}$ & $\begin{array}{l}\text { Ultimate } \\
\text { strength, } \\
\sigma_{\mathrm{b}}(\mathrm{MPa})\end{array}$ & $\begin{array}{l}\text { Elongation, } \\
\delta\end{array}$ \\
\hline 72 & 320 & 460 & 0.174 \\
\hline
\end{tabular}
aluminum alloy and taken from the same sheet, and the related mechanical properties are shown in Table 1. The sample is a funnel-shaped design shown in Fig. 1.

Table 1 Mechanical property for the $L Y 12 C Z$ aluminum alloy

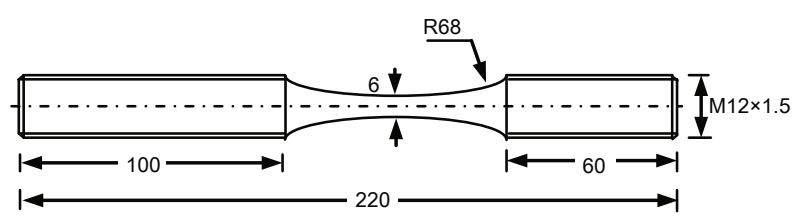

Fig. 1 Schematic diagram of funnel-shaped specimen (unit: mm)

\subsection{Damage parameters of stress corrosion}

Stress corrosion experiments of the LY12CZ aluminum alloy exposed in $3.5 \% \mathrm{NaCl}$ (in weight) solution $(\mathrm{pH}=7.0)$ at room temperature $\left(20{ }^{\circ} \mathrm{C}\right)$ are carried out on the slow strain-rate stress corrosion testing machine (GB/T 15970.4-2000; G49-85-2011). According to the actual experimental conditions, the testing strain-rate is taken as $1 \times 10^{-6} / \mathrm{s}(\mathrm{Li}$ et al., 2010; Kim et al., 2010; Nakano et al., 2012). The stress corrosion life curve declining with effective stress is shown in Fig. 2. As can be seen, the stress corrosion life is constantly decreasing with the increase of the effective stress. Through numerical regression of the 
experimental data, the stress corrosion life model of $\mathrm{LY} 12 \mathrm{CZ}$ in $3.5 \% \mathrm{NaCl}$ (in weight) solution is determined, and the stress corrosion threshold stress is shown to approach $172 \mathrm{MPa}$.

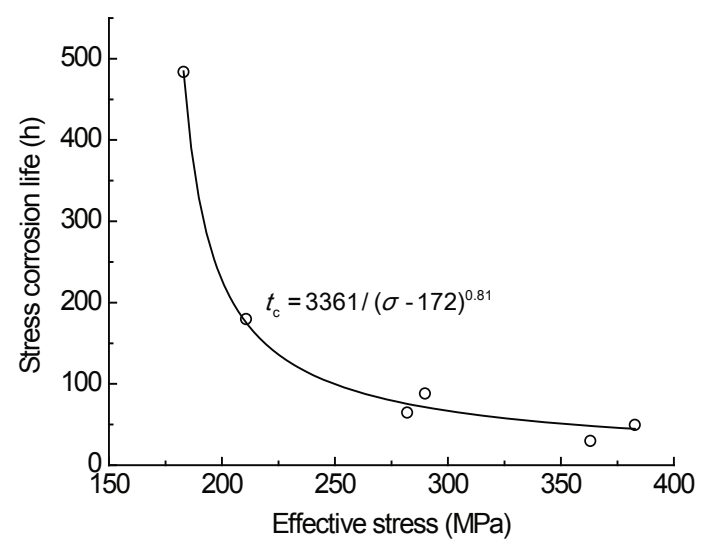

Fig. 2 Stress corrosion life curve of $L Y 12 C Z$ aluminum

\section{3 $S$ - $N$ data of corrosion fatigue}

Corrosion fatigue experiments of the $\mathrm{LY} 12 \mathrm{CZ}$ aluminum alloy are carried out on the MTS809 servo fatigue testing machine, with the loading equipment of samples as shown in Fig. 3. The experiments are done at 10 cycles per second using cyclic stress fluctuations in the form of a sinusoidal wave controlled through a constant stress amplitude (GB/T 20120.1-2006; E466-07-2007). The maximum stress of the two groups of samples (6 samples per group) is set to $400 \mathrm{MPa}$ and $360 \mathrm{MPa}$, respectively, with the load ratio of 0.1 .

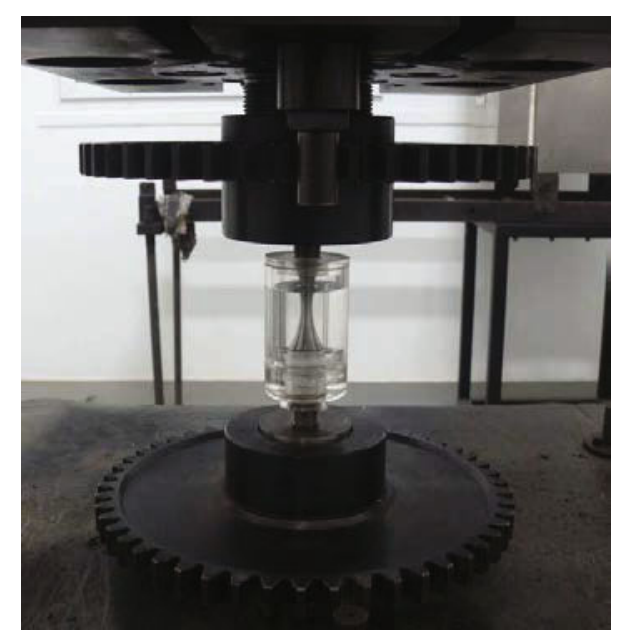

Fig. 3 Loading equipment for corrosion fatigue
The corrosion fatigue $S-N$ data of the LY12CZ aluminum alloy in $3.5 \%$ (in weight) $\mathrm{NaCl}$ solution are shown in Fig. 4. Because of the processing of the samples and the operation factors during testing, the experimental results had certain dispersions. After being averaged, the corrosion fatigue life of the samples at the maximum stress of $400 \mathrm{MPa}$ (average stress $\sigma_{0}=220 \mathrm{MPa}$, stress amplitude $\sigma_{\mathrm{a}}=180 \mathrm{MPa}$ ) is 10084 cycles, and the corrosion fatigue life at the maximum stress of $360 \mathrm{MPa}$ (average stress $\sigma_{0}=$ $198 \mathrm{MPa}$, stress amplitude $\sigma_{\mathrm{a}}=162 \mathrm{MPa}$ ) is 13460 cycles.

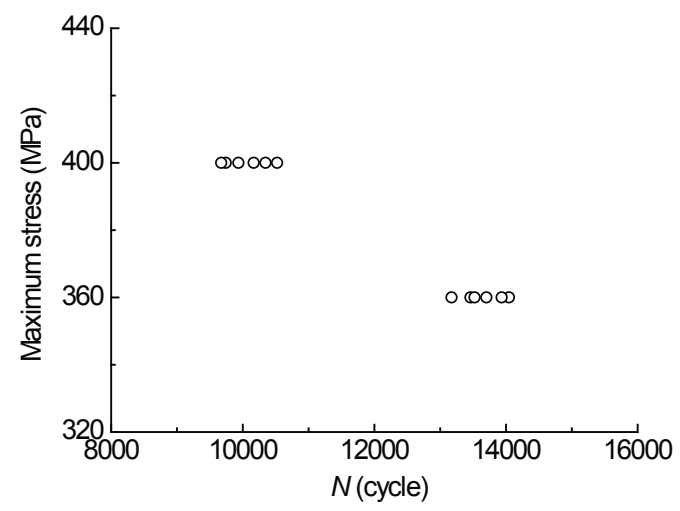

Fig. 4 The $S-N$ data of corrosion fatigue

\section{Damage evolution model of corrosion fatigue}

According to the stress corrosion and corrosion fatigue life data of the $\mathrm{LY} 12 \mathrm{CZ}$ aluminum alloy, the corrosion fatigue damage evolution model is established and the relative damage parameters are determined. On the basis of the considerable experimental data for LY12CZ smooth specimens, Gao et al. (1999) summarized the fatigue life formula, i.e.,

$$
N_{\mathrm{f}}=1.634 \times 10^{9}\left(\frac{466^{4}}{466^{4}-\sigma_{0}^{4}} \sigma_{\mathrm{a}}-43\right)^{-2.1319} .
$$

When only the influence of stress amplitude to fatigue life is considered, the fatigue damage evolution parameters can be determined by fitting the fatigue experimental results under different stress amplitudes with average stress unchanged. Combined with Eq. (5), the formula for fatigue life based on damage evolution can be modified as 


$$
\lg \sigma_{\mathrm{a}}=\lg M\left(\sigma_{0}\right)-\frac{1}{B}\left[\lg N_{\mathrm{f}}+\lg (\mu+1)\right] .
$$

The fatigue damage parameters at $\sigma_{0}=220 \mathrm{MPa}$ are regressed as

$$
M\left(\sigma_{0}\right)=3762.3, B=2.969, \mu=-0.809 \text {, }
$$

and at $\sigma_{0}=198 \mathrm{MPa}$,

$$
M\left(\sigma_{0}\right)=3324.6, B=2.942, \mu=-0.874 \text {. }
$$

Consequently, the corrosion fatigue damage evolution formulas at $\sigma_{0}=220 \mathrm{MPa}$ and $\sigma_{0}=198 \mathrm{MPa}$ are rewritten as

$$
\frac{N}{N_{\mathrm{c}}}=\int_{0}^{1}\left(\frac{(1-D)^{-\psi}}{1+\psi}+\frac{(1-D)^{0.809} N_{\mathrm{c}}}{0.191 N_{\mathrm{f}}}\right)^{-1} \mathrm{~d} D
$$

and

$$
\frac{N}{N_{\mathrm{c}}}=\int_{0}^{1}\left(\frac{(1-D)^{-\psi}}{1+\psi}+\frac{(1-D)^{0.874} N_{\mathrm{c}}}{0.126 N_{\mathrm{f}}}\right)^{-1} \mathrm{~d} D .
$$

Since Eqs. (17) and (18) cannot be explicity integrated, the Gaussian integration method is adopted for computing the corrosion fatigue damage evolution life $(\Delta D=0.001)$. Corrosion fatigue lives based on damage evolution theory vary with the corrosion fatigue damage index $\psi$ (Figs. 5 and 6). As can be seen, the theoretical curve fits quite well with the experimental data when the damage index $\psi$ valued 0.0002 at $\sigma_{0}=220 \mathrm{MPa}$, and the theoretical one fits well with the experimental data when $\psi$ valued 0.001 at $\sigma_{0}=198 \mathrm{MPa}$. In short, all the corrosion fatigue damage parameters can be determined by fitting the experimental results of the relative materials, and thus a complete corrosion fatigue life prediction model based on damage evolution theory is formed.

\section{Conclusions}

Based on the theory of damage mechanics, a corrosion fatigue damage evolution model is proposed. Corrosion fatigue damage is treated as the nonlinear accumulation of stress corrosion damage and fatigue damage. Combined with the experimental

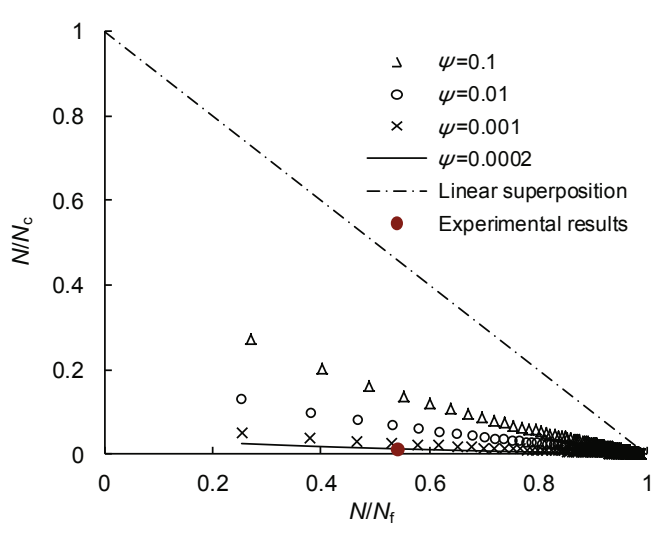

Fig. 5 Corrosion fatigue damage life of the $L Y 12 C Z$ aluminum alloy at $\sigma_{0}=220 \mathrm{MPa}$

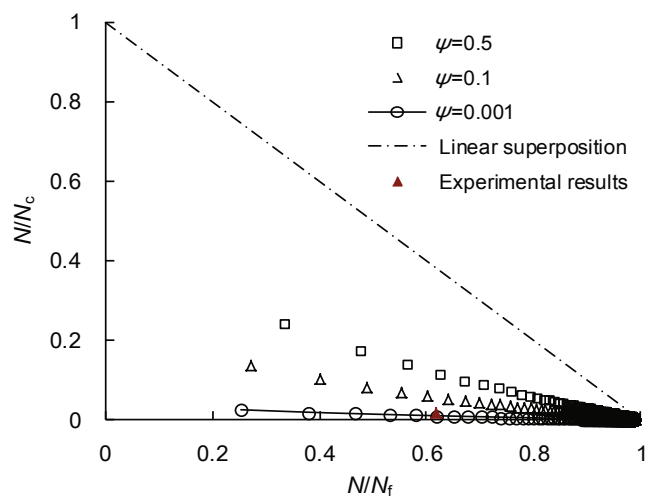

Fig. 6 Corrosion fatigue damage life of the $\mathrm{LY} 12 \mathrm{CZ}$ aluminum alloy at $\sigma_{0}=198 \mathrm{MPa}$

results of the LY12CZ aluminum alloy, the corrosion fatigue damage parameters are determined and the theoretical corrosion fatigue life prediction model of the LY12CZ aluminum alloy is established. This model can provide a new method for the theoretical study of corrosion fatigue and its life prediction.

However, to reduce the number of damage parameters and to determine these damage evolution parameters in convenience, only the influence of alternating stress amplitude on the damage evolution is considered in this paper, recognizing the uncertainty of the physical meaning of these parameters and the poor application of the corrosion fatigue damage model. At the same time, the corrosion fatigue damage evolution parameters may have certain differences for different materials. So the determination of the relative damage parameters should rely on the experimental data of the corresponding material. Thus, the corrosion fatigue damage evolution model will be improved gradually. 


\section{References}

Alamilla, J.L., Espinosa-Medina, M.A., Sosa, E., 2009. Modelling steel corrosion damage in soil environment. Corrosion Science, 51(11):2628-2638. [doi:10.1016/j. corsci.2009.06.052]

Besson, J., 2010. Continuum models of ductile fracture: a review. International Journal of Damage Mechanics, 19(1):3-52. [doi:10.1177/1056789509103482]

Bhuiyan, M.S., Mutoh, Y., Murai, T., et al., 2008. Corrosion fatigue behavior of extruded magnesium alloy AZ61 under three different corrosive environments. International Journal of Fatigue, 30(10-11):1756-1765. [doi:10.1016/j.ijfatigue.2008.02.012]

Chaboche, J.L., 1981. Continuous damage mechanics-A tool to describe phenomena before crack initiation. Nuclear Engineering and Design, 64(2):233-247. [doi:10. 1016/0029-5493(81)90007-8]

Chaboche, J.L., 1988a. Continuum damage mechanics: part I - general concepts. Journal of Applied Mechanics, 55(1):59-64. [doi:10.1115/1.3173661]

Chaboche, J.L., 1988b. Continuum damage mechanics: part II -damage growth, crack initiation and crack growth. Journal of Applied Mechanics, 55(1):65-72. [doi:10. $1115 / 1.3173662]$

E466-07-2007. Standard Practice for Conducting Force Controlled Constant Amplitude Axial Fatigue Tests of Metallic Materials. Annual Book of ASTM Standards, USA.

Fatemi, A., Vangt, L., 1998. Cumulative fatigue damage and life prediction theories: a survey of the state of the art for homogeneous materials. International Journal of $\mathrm{Fa}$ tigue, 20(1):9-34. [doi:10.1016/S0142-1123(97)00081 $-9]$

G49-85-2011. Standard Practice for Preparation and Use of Direct Tension Stress-corrosion Test Specimens. Annual Book of ASTM Standards, USA.

Gao, Z.T., Jiang, X.T., Xiong, J.J., 1999. Fatigue Behavior Test Design and Data Treatment. Beihang University Press, Beijing, China (in Chinese).

GB/T 15970.4-2000. Corrosion of Metals and Alloys-stress Corrosion Testing-Part 4: Preparation and Use of Uniaxially Loaded Tension Specimens. State Bureau of Quality Technical Supervision, Beijing, China (in Chinese).

GB/T 20120.1-2006. Corrosion of Metals and Alloyscorrosion Fatigue Testing-cycles to Failure Testing. State Bureau of Quality Technical Supervision, Beijing, China (in Chinese).

Huang, X.G., Xu, J.Q., 2013. 3D analysis for pit evolution and pit-to-crack transition during corrosion fatigue. Journal of Zhejiang University-SCIENCE A (Applied Physics \& Engineering), 14(4):292-299. [doi:10.1631/jzus. A1200273]

Ishihara, S., Nan, Z.Y., McEvily, A.J., et al., 2008. On the initiation and propagation behavior of corrosion pits during corrosion fatigue process of industrial pure alu- minum. International Journal of Fatigue, 30(9):16591668. [doi:10.1016/j.ijfatigue.2007.11.004]

Jain, J.R., Ghosh, S., 2008. Damage evolution in composites with a homogenization-based continuum damage mechanics model. International Journal of Damage Mechanics, 18(6):533-568. [doi:10.1177/1056789508091 563]

Kermanidis, A.T., Petroyianas, P.V., Pantelakis S.G., 2005. Fatigue and damage tolerance behavior of corroded 2024 T351 aircraft aluminum alloy. Theoretical and Applied Fracture Mechanics, 43(1):121-132. [doi:10. 1016/j.tafmec.2004.12.008]

Kim, S.J., Kim, S.K., Park, J.C., 2010. The corrosion and mechanical properties of Al alloy 5083-H116 in metal inert gas welding based on slow strain rate test. Surface and Coatings Technology, 205(1S):73-78. [doi:10.1016/ j.surfcoat.2010.04.039]

Kotsikos, G., Evans, J.T., Gibson A.G., et al., 1999. Use of acoustic emission to characterize corrosion fatigue damage accumulation in glass fiber reinforced polyester laminates. Polymer Composites, 20(5):689-696. [doi:10. 1002/pc.10392]

Lemaitre, J., 1985. A continuous damage mechanics model for ductile fracture. Journal of Engineering Materials and Technology, 107(1):83-89. [doi:10.1115/1.3225775]

Lemaitre, J., Chaboche, J.L., 1990. Mechanics of Solid Materials. Cambridge University Press, Cambridge, UK. [doi:10.1017/CBO9781139167970]

Li, S.J., Zhang, Z.G., Akiyamab, E.J., et al., 2010. Evaluation of susceptibility of high strength steels to delayed fracture by using cyclic corrosion test and slow strain rate test. Corrosion Science, 52(5):1660-1667. [doi:10. 1016/j.corsci.2010.02.005]

Misak, H.E., Perel, V.Y., Sabelkin, V., et al., 2013. Corrosion fatigue crack growth behavior of 7075-T6 under biaxial tension-tension cyclic loading condition. Engineering Fracture Mechanics, 106:38-48. [doi:10.1016/j. engfracmech.2013.04.004]

Nakano, H., Oue, S., Taguchi, S., et al., 2012. Stress-corrosion cracking property of aluminum-magnesium alloy processed by equal-channel angular pressing. International Journal of Corrosion, 2012:1-8. [doi:10.1155/2012/ 543212]

Ohata, M., Fukahori, T., Minami, F., 2010. Damage model for predicting the effect of steel properties on ductile crack growth resistance. International Journal of Damage Mechanics, 19(4):441-459. [doi:10.1177/10567895091 03704]

Raykar, N.R., Maiti, S.K., Singh Raman, R.K., 2011. Modelling of mode-I stable crack growth under hydrogen assisted stress corrosion cracking. Engineering Fracture Mechanics, 78(18):3153-3165. [doi:10.1016/j.engfrac mech.2011.07.013]

Tang, Z.B., Li, Q., 2007. Review: Advances in research of stress-assisted corrosion fatigue problem. Journal of 
Zhejiang University-SCIENCE A, 8(2):221-227. [doi:10. 1631/jzus.2007.A0221]

Wu, L., Chen, Z.T., Sun, Q., 2004. Damage mechanics model for the initiation life of stress corrosion cracking. Journal of Mechanical Strength, 26(S):58-59 (in Chinese).

Zhang, G.D., Zhao, Y.F., Xue, F., et al., 2011. Creep-fatigue interaction damage model and its application in modified 9Cr-1Mo steel. Nuclear Engineering and Design, 241(12):4856-4861. [doi:10.1016/j.nucengdes. 2011.08.076]

Zhao, W.M., Xin, R.F., He, Z.R., et al., 2012. Contribution of anodic dissolution to the corrosion fatigue crack propagation of $\mathrm{X} 80$ steel in 3.5 wt.\% NaCl solution. Corrosion Science, 63:387-392. [doi:10.1016/j.corsci.2012.06. 016]

\section{中文概要：}

\section{本文题目：一种腐蚀疲劳损伤的非线性累加演化模型}

\section{A nonlinear cumulative evolution model for corrosion fatigue damage}

研究目的：提出一种新的腐蚀疲劳损伤演化模型, 建立基于损伤演化的腐蚀疲劳寿命预测模型。

创新要点: 将应力腐蚀损伤与疲劳损伤非线性耦合, 建立腐蚀疲劳损伤演化律, 依托实验确定腐蚀瘦劳 损伤演化参数，形成基于损伤演化律的腐蚀疲劳寿命预测模型。

研究方法: 采用理论研究与实验验证相结合的研究方法。选取特定材料设计应力腐蚀实验, 回归应力腐 蚀门槛值应力和损伤参数（图 2); 查阅疲劳实验数据建立变幅疲劳损伤模型, 将应力腐蚀 损伤与变幅疲劳损伤非线性累加形成腐蚀疲劳损伤非线性演化模型。根据腐蚀疲劳实验结 果，验证腐蚀疲劳损伤演化模型并确定非线性损伤累加参数（图 5 和 6），形成基于损伤演 化律的腐蚀疲劳寿命预测模型。

重要结论: 从损伤力学角度, 将材料的腐蚀疲劳损伤处理成应力腐蚀损伤与疲劳损伤的非线性累加, 形 成腐蚀疲劳损伤演化模型。结合 LY $12 \mathrm{CZ}$ 铝合金的试验结果, 验证了损伤演化模型的可行性。 该方法可以为材料腐蚀疲劳的寿命评价研究提供新的思路。 